\title{
Genetic diversity and epidemiology of infectious hematopoietic necrosis virus in Alaska
}

\author{
E. J. Emmenegger ${ }^{1, *}$, T. R. Meyers ${ }^{2}$, T. O. Burton ${ }^{3}$, G. Kurath ${ }^{1}$ \\ ${ }^{1}$ Western Fisheries Research Center, Biological Resources Division, U.S. Geological Survey, 6505 NE 65th St. Seattle, \\ Washington 98115, USA \\ ${ }^{2}$ Juneau Fish Pathology Laboratory, Alaska Department of Fish and Game, PO Box 25526, Juneau, Alaska 99802, USA \\ ${ }^{3}$ Anchorage Fish Pathology Laboratory, Alaska Department of Fish and Game, 333 Raspberry Road, Anchorage, \\ Alaska 99518, USA
}

\begin{abstract}
Forty-two infectious hematopoietic necrosis virus (IHNV) isolates from Alaska were analyzed using the ribonuclease protection assay (RPA) and nucleotide sequencing. RPA analyses, utilizing 4 probes, N5, N3 (N gene), GF (G gene), and NV (NV gene), determined that the haplotypes of all 3 genes demonstrated a consistent spatial pattern. Virus isolates belonging to the most common haplotype groups were distributed throughout Alaska, whereas isolates in small haplotype groups were obtained from only 1 site (hatchery, lake, etc.). The temporal pattern of the GF haplotypes suggested a 'genetic acclimation' of the G gene, possibly due to positive selection on the glycoprotein. A pairwise comparison of the sequence data determined that the maximum nucleotide diversity of the isolates was $2.75 \%$ (10 mismatches) for the NV gene, and 1.99\% (6 mismatches) for a 301 base pair region of the $\mathrm{G}$ gene, indicating that the genetic diversity of IHNV within Alaska is notably lower than in the more southern portions of the IHNV North American range. Phylogenetic analysis of representative Alaskan sequences and sequences of 12 previously characterized IHNV strains from Washington, Oregon, Idaho, California (USA) and British Columbia (Canada) distinguished the isolates into clusters that correlated with geographic origin and indicated that the Alaskan and British Columbia isolates may have a common viral ancestral lineage. Comparisons of multiple isolates from the same site provided epidemiological insights into viral transmission patterns and indicated that viral evolution, viral introduction, and genetic stasis were the mechanisms involved with IHN virus population dynamics in Alaska. The examples of genetic stasis and the overall low sequence heterogeneity of the Alaskan isolates suggested that they are evolutionarily constrained. This study establishes a baseline of genetic fingerprint patterns and sequence groups representing the genetic diversity of Alaskan IHNV isolates. This information could be used to determine the source of an IHN outbreak and to facilitate decisions in fisheries management of Alaskan salmonid stocks
\end{abstract}

KEY WORDS: IHNV · Salmon · Alaska · Diversity $\cdot$ Epidemiology $\cdot$ Phylogeny

\section{INTRODUCTION}

In Alaska, infectious hematopoietic necrosis virus (IHNV) is enzootic among essentially all anadromous stocks of sockeye salmon Oncorhynchus nerka and some kokanee stocks. Occasional detections and outbreaks of the virus have occurred in wild and cultured chum $O$. keta and chinook $O$. tshawytscha salmon (Follett et al. 1987). A single isolation of IHNV was detected in a coho salmon $O$. kisutch taken from waters

\footnotetext{
•E-mail: evi_emmenegger@usgs.gov
}

also containing spawning sockeye salmon (T.R.M. pers. comm.). Many isolations of IHNV have been obtained from various stocks of sockeye salmon and substantial fluctuations in prevalence and the virus titers for particular stocks have been observed (Meyers et al. 1990). However, little genetic information is known about these viral isolates.

Modern tools of molecular epidemiology can distinguish virus strains on a genetic basis. This information can identify links between multiple infections, aid in determining the modes of viral strain transmission, and provide estimates of the rate of virus evolution through 
space, time, and within a host species. The 2 techniques used in this study to genetically characterize the IHNV genes were ribonuclease protection assay (RPA) and nucleotide sequencing. RPA produces a 'genetic fingerprint' of each region of the genome studied. The advantage of RPA is its ability to rapidly analyze large regions of the genome of many isolates. A limitation of the RPA is that not all nucleotide differences between isolates are detected (Meyers et al. 1985, Winter et al. 1985). Sequencing deciphers the primary nucleotide structure of the genome; however, this finer resolution limits the amount analyzed and thus only selected regions of the genome are sequenced.

The IHNV genome consists of a linear molecule of negative sense, non-segmented, single-stranded RNA encoding 6 genes that code for 5 structural proteins and 1 nonvirion protein (Kurath \& Leong 1985, Kurath et al. 1985). The 3 genes analyzed in this study include the nucleoprotein $(N)$, glycoprotein $(G)$, and nonvirion (NV) protein genes, which comprise $30 \%$ of the genome. The nucleocapsid protein, which encapsidates the genome, may be involved in modulating the immune response (Oberg et al. 1991) and regulating transcription (Banerjee \& Barik 1992). The glycoprotein initiates infection by binding to and inducing fusion into the fish host cell, and is the primary antigen to elicit a humoral immune response in the host (Rose \& Schubert 1987, Engelking \& Leong 1989). The NV gene is the taxonomic hallmark for placing IHNV into the newly established Novirhabdovirus genus of the family rhabdoviridae (Walker et al. in press). It codes for a nonvirion protein of small size (111 amino acids) with an unknown function (Kurath \& Leong 1985).

Forty-two IHNV isolates were genetically characterized in this study. These isolates were sampled from 23 sites in Alaska over a 19 yr period and came from various watersheds, from both hatchery and wild fish, from different salmonid age classes, and from various salmonid species (Table 1 and Fig. 1). The complete $N$, $G$, and NV genes were analyzed by RPA, and a variable region of the G gene and the entire NV gene were sequenced to determine the genetic diversity among these isolates. The possible epidemiological relationships among the isolates were explored on a spatial andior temporal scale.

\section{MATERIALS AND METHODS}

Virus isolates. Forty-two Alaska isolates of IHNV were obtained as frozen aliquots of cell culture supernatant. Each virus sample was filtered through a 0.45 micron filter and a $100 \mu$ portion was inoculated onto a confluent monolayer of epithelioma papulosum cyprini (EPC) cells (Fijan et al. 1983) in minimum essential medium supplemented with $10 \%$ fetal calf serum (MEM-10). Infected cultures were incubated at $15^{\circ} \mathrm{C}$ until the monolayer started to slough off, typically 6 or $7 \mathrm{~d}$ post-inoculation. Infected cells and media for each virus isolate were centrifuged and $1.0 \mathrm{ml}$ aliquots of supernatant were frozen at $-70^{\circ} \mathrm{C}$. These served as the virus stock used in the study. The reference virus strain, RB1, isolated in 1975 from steelhead Oncorhynchus mykiss at the Round Butte Hatchery on the Deschutes River, Oregon (Hsu et al. 1986), was cultured under the same conditions. The RB1 virus was used to generate the RPA probes and served as positive control RNA (Kurath et al. 1995).

RNA extraction. Forty-two Alaskan IHNV isolates were individually inoculated onto confluent EPC monolayers in $25 \mathrm{~cm}^{2}$ flasks containing MEM-10 media and incubated at $15^{\circ} \mathrm{C}$. During early signs of $\mathrm{CPE}$, typically 48 to $72 \mathrm{~h}$ post-inoculation, total RNA from infected cells was harvested using a guanidium thiocyanate denaturing solution followed by phenol/ chloroform extraction and isopropanol precipitations (Gilman 1994). RNA aliquots of $10 \mu \mathrm{l}$ for each viral isolate were stored at $-70^{\circ} \mathrm{C}$. Each viral RNA preparation was quantified by optical density at $260 \mathrm{~nm}$ on a spectrophotometer. Quantity and quality of the viral RNA were also assessed by electrophoresis on a denaturing formaldehyde agarose gel (Sambrook 1989). The RNA extraction was repeated 2 times for each virus isolate to obtain sufficient quantities of target viral RNA and to verify the reproducibility of the RPA using different RNA preparations of the same isolate.

RPA. The general RPA protocol and reagents used in this assay are described in Winter et al. (1985). An outline of the procedure and modifications from the Winter methods are listed below. Four anti-sense 32P-UTP radiolabeled RNA probes, designated N5, N3, GF, and NV, were used to analyze 3 entire genes of the IHNV genome including the complete open reading frames and flanking untranslated regions (Fig. 2). Two overlapping $N$ gene probes were used to assess the complete $N$ gene, since a full-length $N$ gene probe created illegible RPA banding patterns (G.K., E.J.E. \& D. Anderson unpubl.). Cloning, transcription, and the RPA assay protocols were previously described by Kurath et al. [1995) for analysis of the NV gene of IHNV and the same procedures were used for $\mathrm{N}$ and $\mathrm{G}$ gene analysis. Controls for each set of assays included: an RB1 positive control, an RNA transcript (N5, N3, GF, or NV) positive control, and 2 negative controls. The RB1 positive control reaction contained RNA extracted from cell cultures infected with the RB1 reference strain. The RNA transcript positive controls were unlabeled plus sense RNA transcribed from the same plasmids used to make the probes. One negative control (NR) consisted of a reaction in which no target RNA was 


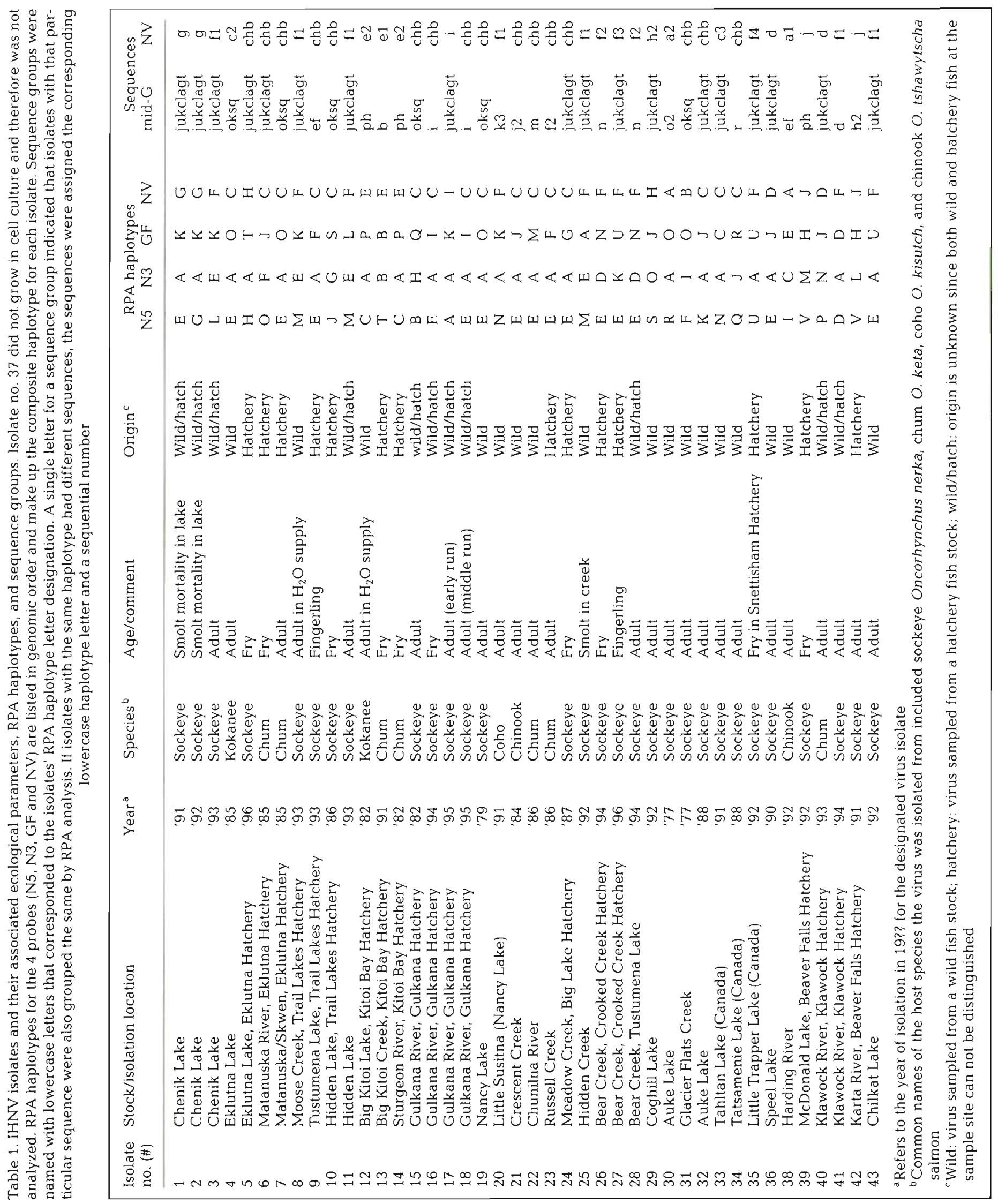




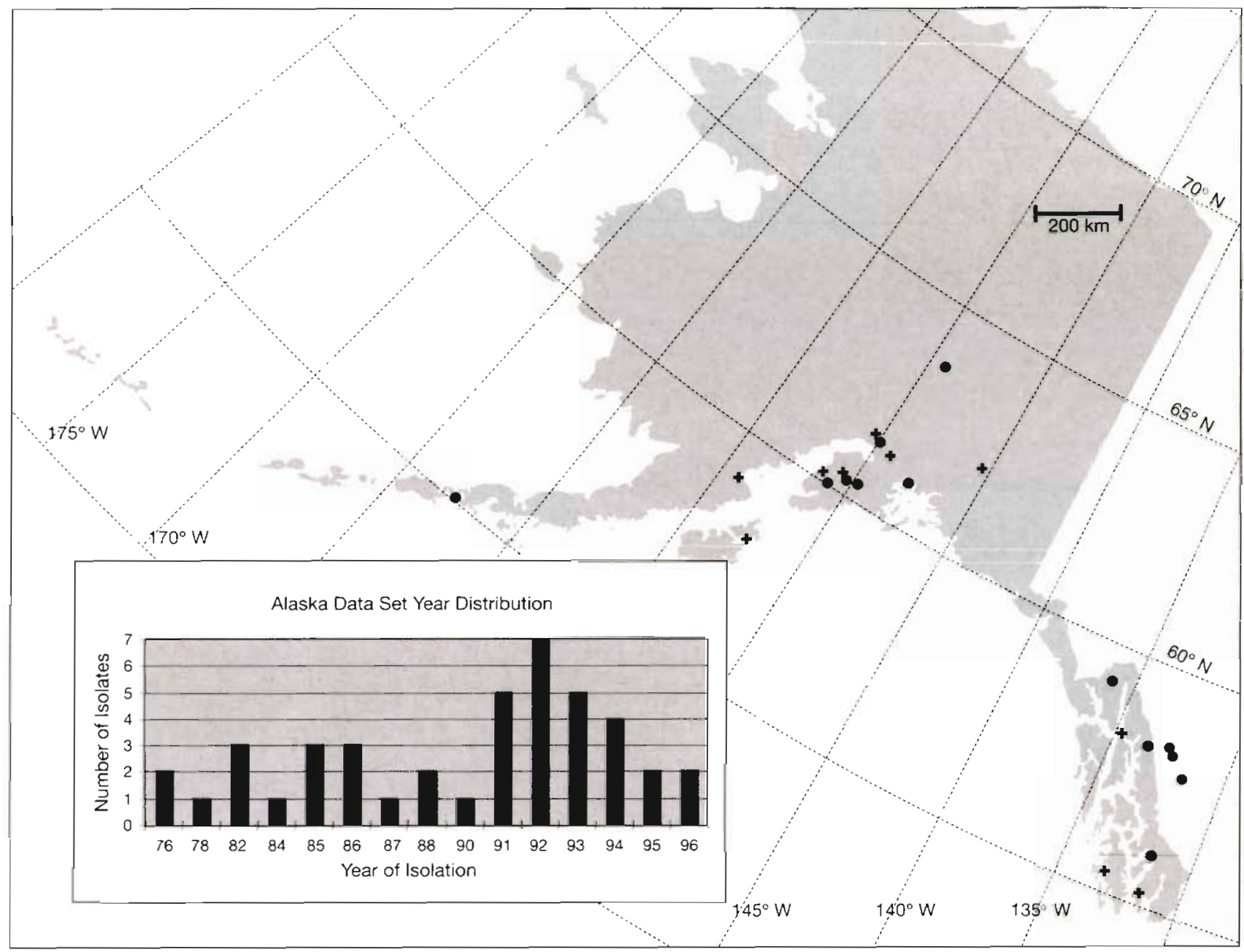

Fig. 1. Twenty-three IHNV isolation sites are plotted from their latitudinal and longitudinal coordinates. Circles depict 13 sites with only 1 isolate analyzed each. Plus signs indicate 10 sites with multiple isolates analyzed. The inset graph displays the year distribution of the virus isolates

added and the other negative control $(\mathrm{Pr})$ contained probe with no target RNA and no RNases in the digestion step. The molecular weight marker consisted of thirteen 32P-UTP radiolabeled RNA transcripts ranging in size from 26 to 1929 nucleotides (G.K. unpubl.). Each of the 42 viral isolate RNAs were analyzed by RPA a minimum of 3 times with earh probe (N5, N3. GF, and NV). The banding patterns of all the isolates were compared and those isolates with identical cleavage patterns were defined as sharing one haplotype for a specific probe. A haplotype was defined as a specific banding pattern of cleavage fragments. A haplotype group was defined as a set of virus isolates that shared an identical haplotype. Isolates with different banding patterns, those with at least a single band difference, were considered to be distinct haplotypes. A haplotype was denoted by a single capital letter.

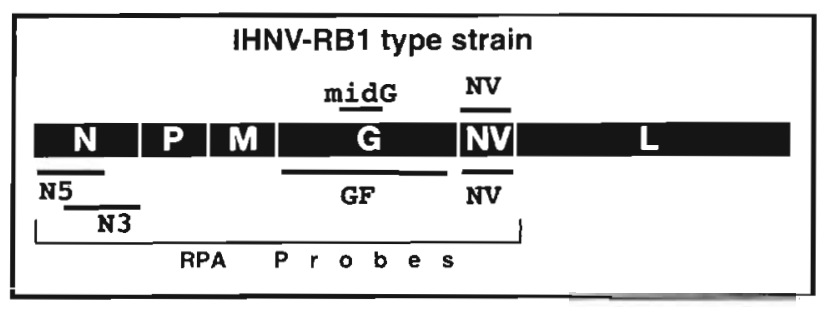

Fig. 2. Diagrammatic IHNV genomic RNA displaying the 2 regions sequenced (above) and the 4 RPA probes used to analyze the $N, G$, and NV genes (below). The midG region corresponds to 301 base pairs, from nucleotide 688 to 989 of the $G$ gene. The full-length NV gene consisting of 364 base pairs was sequenced. The N5, N3, GF and NV antisense probes were complementary to nucleotides $0-768$, $379-1289,0-1610$, and $0-370$ on their respective gene mRNA. Nucleotide sequences of each of the genes ( $N, G, N V)$ are available under GenBank accession numbers U50402, U50401, and U47846 respectively 
Nucleotide sequence analysis. A $301 \mathrm{bp}$ region, from nucleotide 688 to 989 , on the IHNV G gene and the full-length NV gene (364 nucleotides) were sequenced for each of the 42 virus isolates (Fig. 2). The midG gene region was selected for sequencing since it contains a putative antigenic determinant and is a region of high sequence diversity (Nichol et al. 1995, Huang et al. 1996). The template for reverse transcription polymerase chain reaction (RT-PCR) was a 1:20 dilution of cell culture supernatant for each isolate. The RT-PCR used specific sense primers 5' AGAGATCCCTACACCAGAGAC 3' and 5' AGCATCAAATCCGTACCC 3', and antisense primers 5' GGTGGTGTTGTTTCCGTGCAA $3^{\prime}$ and 5' TTCTCTGTGAGTCGCGC 3' for the midG region and NV gene, respectively. Second round primers for the nested PCR used sense primers 5' TCACCCTGCCAGACTCATTGG $3^{\prime}$ and 5' TCCCTCCCCACCAGACA $3^{\prime}$, and antisense primers 5' ATAGATGGAGCCTTTGTGCAT 3 ' and 5' CGCTTGAGTTTTTTTGCAC $3^{\prime}$ for the midG region and NV gene, respectively. The reaction conditions for the RT-and nested PCR were as described by Huang et al. (1996). The final product of the nested PCR was sequenced with a fluorescent dye terminator cycle sequencing kit (Applied Biosystems) using the second round PCR primers as sequencing primers and following the manufacturer's protocols. The raw nucleotide sequence data was edited using ABl Prism Sequence Analysis 2.1.1 software. Sequence files were further edited, aligned, and analyzed by MacVector 6.0 and AssemblyLIGN 1.0.9 applications (Oxford Molecular Group). For the phylogenetic analyses, input files were configured in SeqPup $0.6 \mathrm{f}$ and phylogenies determined using Phylip 3.572 (Felsenstein 1993). In Phylip, each input file was bootstrapped 1000 times and analyzed by both DNA parsimony and neighborjoining programs. Bootstrap values exceeding $70 \%$ were considered to indicate significant relatedness (Hillis \& Bull 1993, Salminen et al. 1997).

\section{RESULTS}

\section{RPA haplotypes}

The RPA analyses of all 42 isolates resulted in $22,15,21$, and 10 haplotypes being discerned using the 4 probes, N5, N3, GF and NV, respectively. The representative haplotype banding patterns of the GF probe are displayed in Fig. 3. The N5, N3, and NV haplotype patterns are not shown. Haplotype banding patterns for each probe were reproducible for repeated RPA reactions of the same isolate. The sizes of the haplotype groups, defined as the number of isolates represented by a specific haplotype, varied with the different probes (Table 2). In light of these results, we defined the following size classes: large haplotypes represented 11 or more isolates, intermediate haplotypes represented 4 to 6 isolates, small haplotypes represented 2 to 3 isolates, and unique haplotypes were patterns of single isolates that were not identical to any other isolates for a particular probe. Using these definitions, the N5 probe discerned 1 large haplotype, 4 small haplotypes, and 17 unique haplotypes. The N3 probe discerned 1 large, 1 intermediate, 1 small, and 12 unique haplotypes. Interestingly, the GF probe did not identify any large haplotypes, but there were 3 intermediate, 6 small, and 12 unique haplotypes with

Table 2. Haplotype group size distribution with each of the 4 RPA probes. Number of isolates represented by each haplotype is listed in parentheses. Unique haplotypes only represented 1 isolate each and the total number of unique haplotypes for each RPA probe are listed in parentheses at the end of the row. Lower table summarizes the number of isolates (by percentages) in each group size classification for each RPA probe

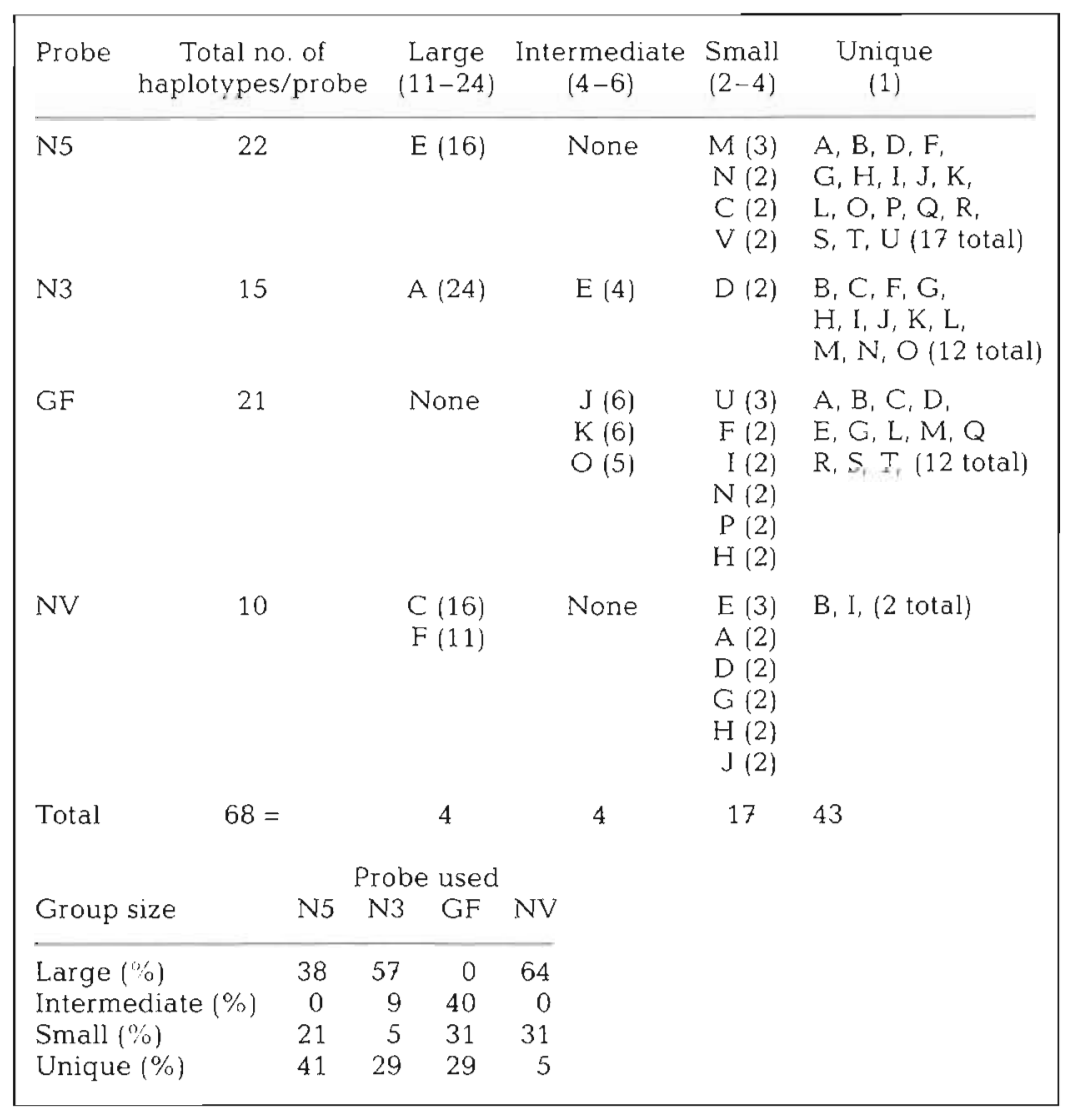




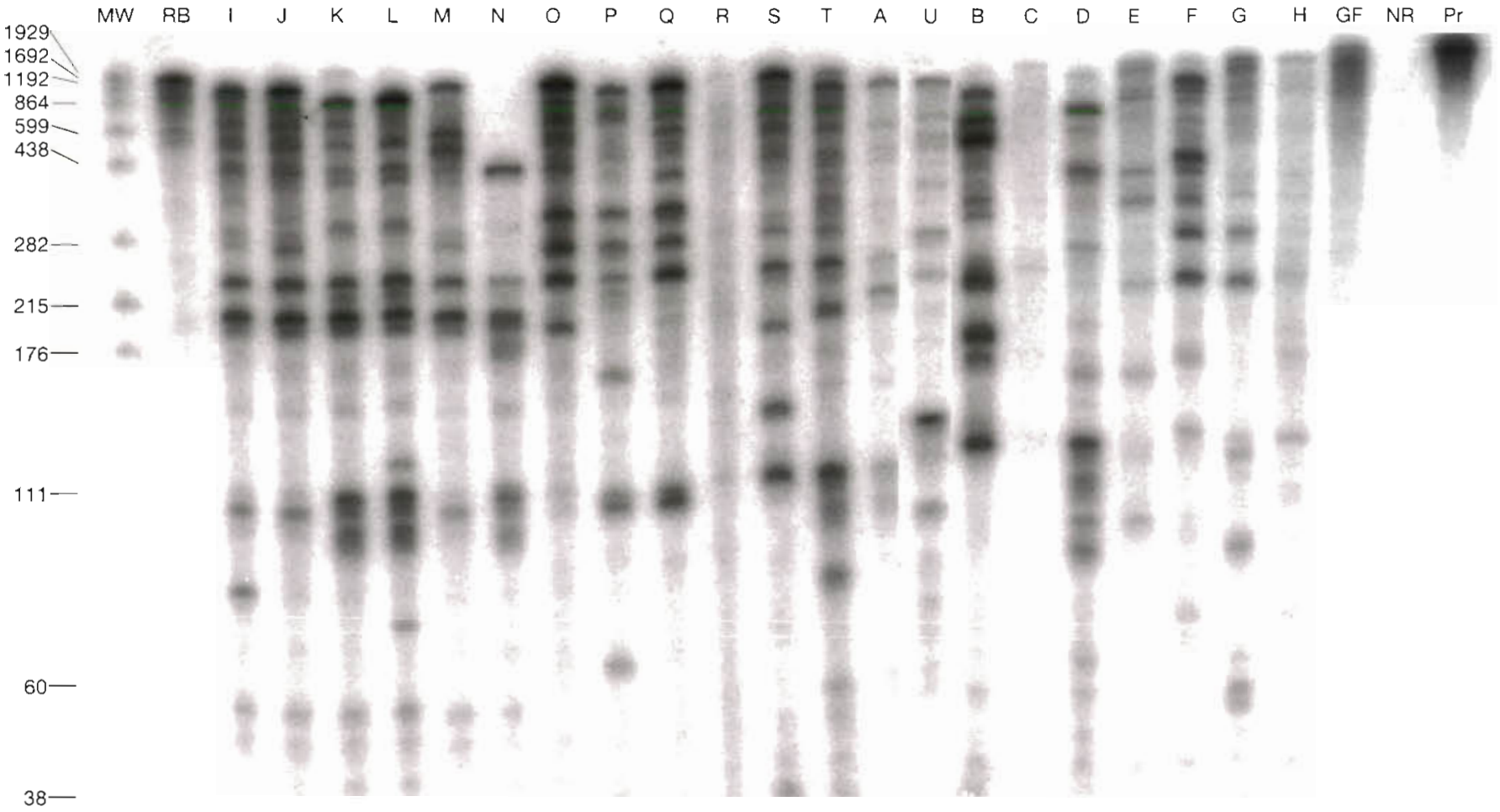

Fig. 3. RPA cleavage fragment patterns of the $21 \mathrm{GF}$ haplotypes representing the Alaska IHNV isolates analyzed. Listed at the top of each lane is the GF haplotype letter or the RPA control reactions (RB, GF NR, and Pr). RB (total RNA extracted from cells infected with the RB1 [Round Butte] strain of IHNV), and GF (G gene mRNA transcript) both are perfectly complimentary with the probe and formed a stable heteroduplex resulting in 1 band near the top of the gel for each control. The negative control, NR, with no target resulted in the entire probe being degraded by the RNase enzymes and therefore no bands appeared. For the Pr negative control there was no addition of target RNA or RNase enzymes to the reaction, which leaves the probe entirely intact. MW: molecular weight markers. Numbers listed to the left of the bands in the first lane indicate the size of the RNA MW markers in. nucleotides

this probe. The NV probe identified 2 large, 6 small and only 2 unique haplotypes.

The haplotype identified for each isolate with each of the 4 probes is shown on Table 1 . In many cases the isolates that grouped together with 1 probe were not exactly the same as the groupings determined with other probes, indicating that additional information was obtained from the different regions of the viral genome assessed by the different probes.

\section{RPA spatial trends}

Spatial analysis of the RPA haplotype data consisted of plotting the haplotypes identified with each probe at the location of isolation. For each virus isolate latitude and longitude coordinates were plotted on an Alaska map and on an enlarged section of Cook Inlet, Alaska. The most significant and consistent trend observed was that isolates from all large and intermediate-sized haplotypes identified by the 4 probes were geographically dispersed throughout Alaska. In general, isolates from small-sized haplotypes tended to be spatially re- stricted (i.e. isolates with the identical haplotypes from a small group were either from the same site or sampled from a nearby location less than $40 \mathrm{~km}$ away). These spatial trends are demonstrated on the Alaska map for the GF haplotypes (Fig. 4). Maps for the N5, N3, and NV haplotypes are not shown, but they displayed a similar spatial distribution. Out of the 17 smallsized haplotypes determined from the RPA analyses with all 4 probes, 13 were spatially restricted and 4 were exceptions to this trend since they were geographically separated. The exceptions included the N5 haplotype N, GF haplotypes F and U, and the NV haplotype $\mathrm{H}$ (Table 1 ).

\section{RPA temporal trends}

Temporal analysis plotted the year of isolation, the haplotype, and location of each virus simultaneously on the Alaska and Cook Inlet maps (data not shown). No consistent overall temporal trend was identified for the haplotypes generated with the N5, N3, and NV probes. The GF haplotypes had the strongest temporal 


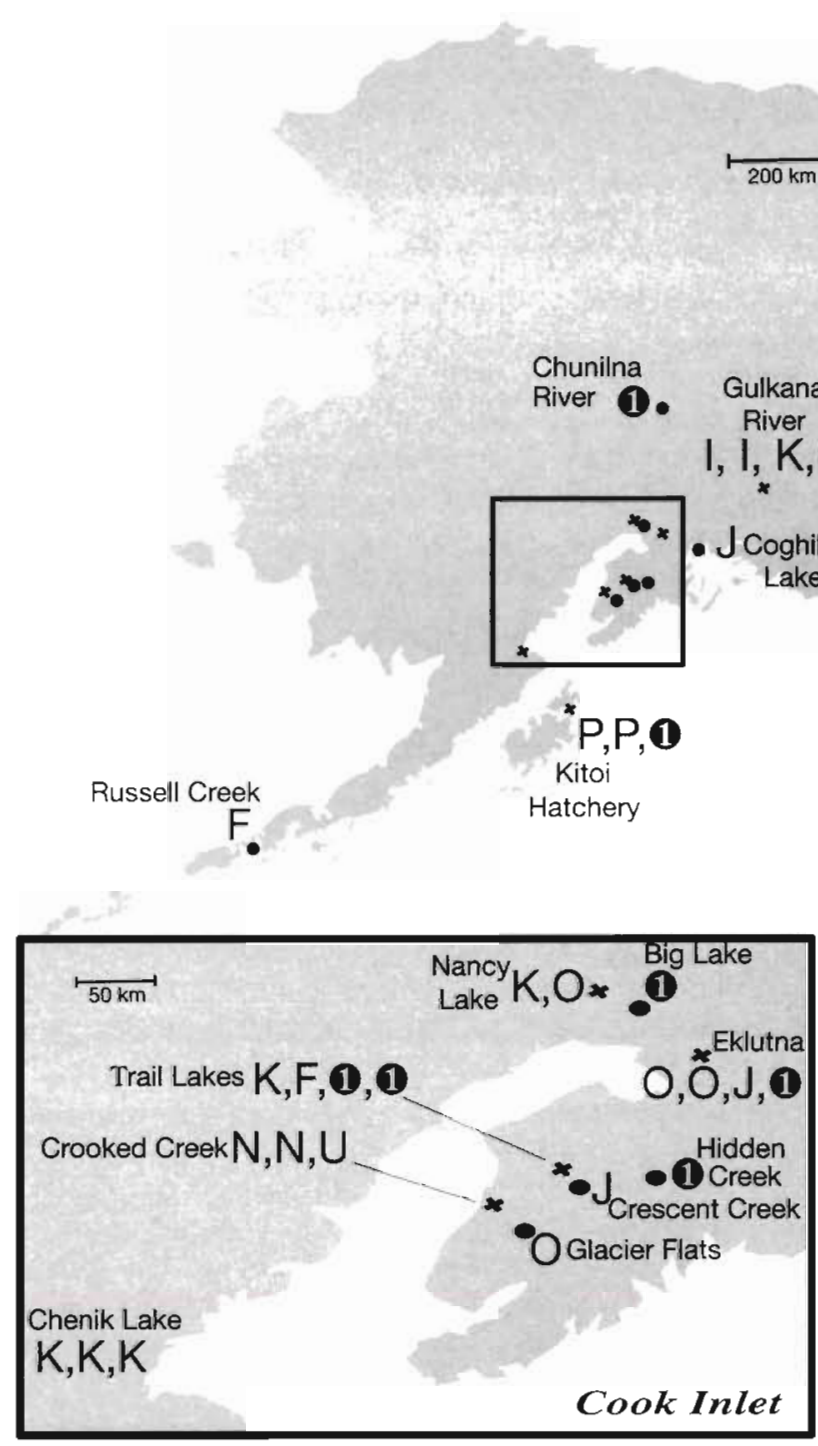

pattern. In several cases, a GF haplotype was present for a contiguous interval and then was no longer present (Fig. 5). For example, the haplotype group $O$ occurred during the years from 1977 to 1985, but was not observed among the 26 isolates collected after 1985, despite sampling at sites that previously had haplotype $O$ strains. The small $\mathrm{P}$ haplotype was present only in 1982. Further, the $O$ and $P$ haplotype patterns were almost identical (Fig. 3), indicating they are closely related genetically and that the $P$ haplotype may have evolved from the $O$ haplotype. The J haplotype first appeared in 1984 and lasted until 1993. The $O$ and $J$ banding patterns share some bands, but clearly have some unique bands, indicating
Fig. 4. Location of RPA GF haplotypes displayed on an Alaska map and an inset map of Cook Inlet, Alaska. Legend lists the GF haplotypes and in parentheses the number of isolates represented by that haplotype. The (1) symbol signifies unique haplotypes represented by only 1 isolate and large capital letters indicate GF haplotypes of IHNV isolates from the locations indicated

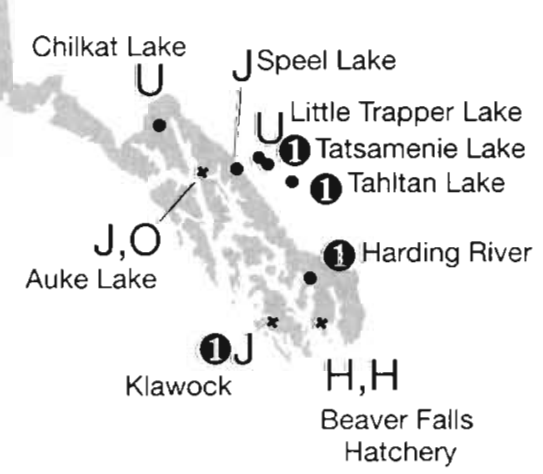

\begin{tabular}{|lc|}
\hline \multicolumn{2}{|c|}{ GF haplotypes } \\
\hline$J_{(6)}$ & $\mathbf{K}_{(6)}$ \\
$\mathbf{O}_{(5)}$ & $\mathbf{U}_{(3)}$ \\
$\mathbf{F}_{(2)}$ & $\mathbf{I}_{(2)}$ \\
$\mathbf{N}_{(2)}$ & $\mathbf{P}_{(2)}$ \\
$\mathbf{H}_{(2)}$ & $\mathbf{1}(12)$ \\
(n)= \#of isolates/haplotype \\
\hline
\end{tabular}

several sequence differences exist between them (Fig. 3). The small F haplotype group with 2 isolates was present in 1986 and 1993. In 1991 the K haplotype appeared and was present through 1995. The J and K haplotype banding patterns are quite similar, whereas

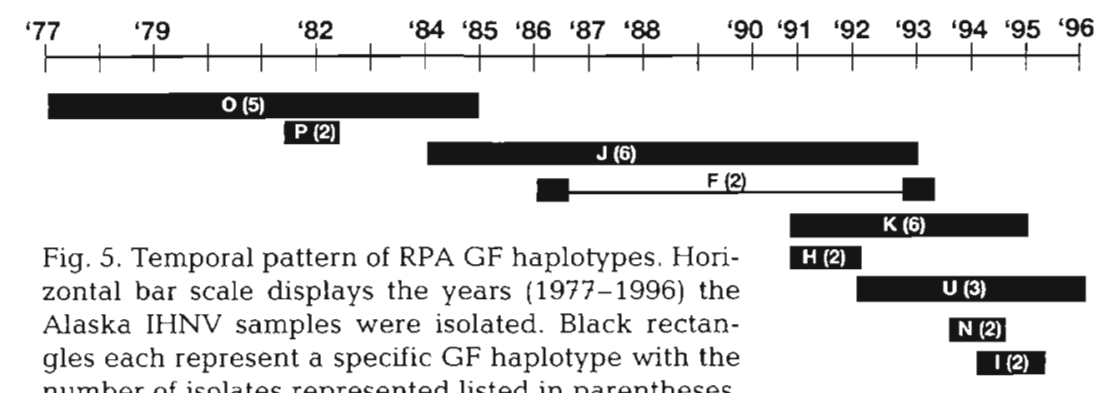
number of isolates represented listed in parentheses. The length of the rectangle reflects the time span a particular GF haplotype was present in Alaska 
the F pattern is distinctly different (Fig. 3), indicating the $\mathrm{K}$ haplotype may have evolved from the $\mathrm{J}$ haplotype, and that $F$ haplotype may represent a virus from an exogenous source. In 1991 and 1992 the $\mathrm{H}$ and $U$ patterns appeared, respectively, with $U$ being present until the last sample year 1996 and the small $H$ haplotype was only seen for $2 \mathrm{yr}$. In later years (1994-1995), the small-sized haplotypes $\mathrm{N}$ and I were also present. It should be noted that the absence of a particular haplotype in the 1990s does not seem to be accounted for by sampling bias, since the majority of the samples were from the later years (Fig. 1 inset).

\section{RPA composite haplotypes}

For each virus isolate, the haplotype designations identified with each of the 4 RPA probes were listed in genomic order $(\mathrm{N} 5 ; \mathrm{N} 3 ; \mathrm{GF} ; \mathrm{NV})$ to generate a composite haplotype that combined all of the RPA data. The 42 Alaskan isolates analyzed by RPA had 36 different composite haplotypes (Table 1). Isolates with identical composite haplotypes are considered most closely related at the genetic level within the detection limits of this assay system (i.e. not all mismatches are detected by the RPA methodology). There were 4 pairs of isolates each with identical composite haplotypes and 1 set of 3 isolates with identical composite haplotypes. Isolates with identical composite haplotypes were plotted on Alaska and Cook Inlet maps (Fig. 6). Out of the 5 identical composite haplotype sets, 4 were located either at the same site or from a site in close proximity. The only exception to this spatial localization was
Isolate 9 from Tustumena Lake in southcentral Alaska which had an identical composite haplotype, EAFC, with an isolate (\# 23) from the Aleutian Islands (Fig. $6^{*}$ ). Sequencing of the midG gene regions revealed that 4 mismatches between these isolates were not detected by RPA methodology, indicating less genetic relatedness than was suggested by RPA.

Comparisons of multiple isolates from the same site provided epidemiological insights. In 1994 at Crooked Creek Hatchery, the sockeye fry from Bear Creek, a tributary to Tustumena Lake, had an outbreak of IHNV (\# 26) with a composite haplotype of EDNF. Later that year, reproductive fluids sampled at Tustumena Lake from returning adults had IHNV (\# 28) with an identical composite haplotype of EDNF. The fingerling progeny of these adults, reared at Crooked Creek Hatchery had an outbreak of IHNV (\# 27) in the spring of 1996 with a composite of EKUF, which differed in 2 of the 4 gene regions analyzed ( $\mathrm{N} 3$ and GF). This suggested that the EDNF strain of IHNV present at 2 different locations in 1994 was associated with the Tustumena Lake watershed, since it was isolated in spawning adults and juveniles from the same stock. The subsequent observation of different haplotypes in spawning adults and their direct descendents documents the diversity of IHNV at the Crooked Creek Hatchery.

At Gulkana Hatchery, 2 of the 4 isolates analyzed had identical IHNV composite haplotypes. Sockeye fry at the hatchery in 1994 had an outbreak of IHNV with a composite haplotype of EAIC and a year later returning adults from the middle of the spawning run had the same composite haplotype (\#16\&18). In contrast, the early run of the 1995 Gulkana Hatchery sockeye had a

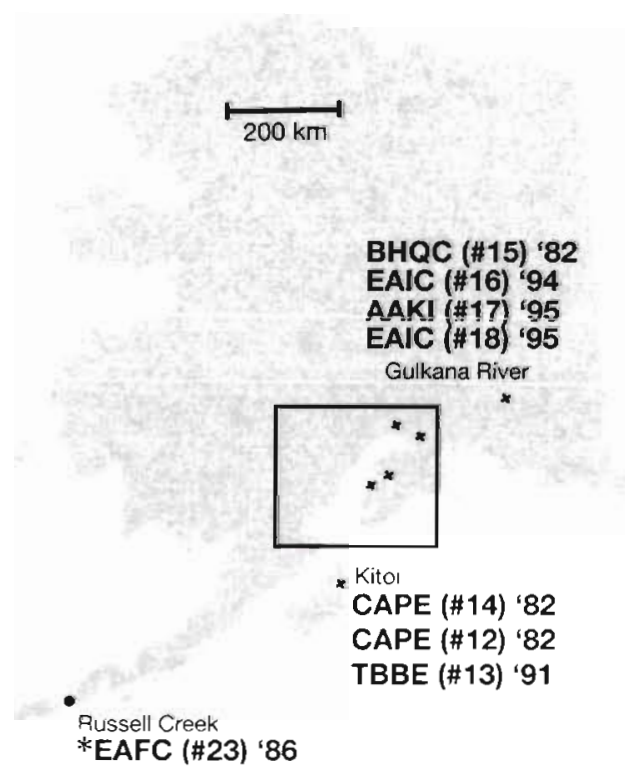

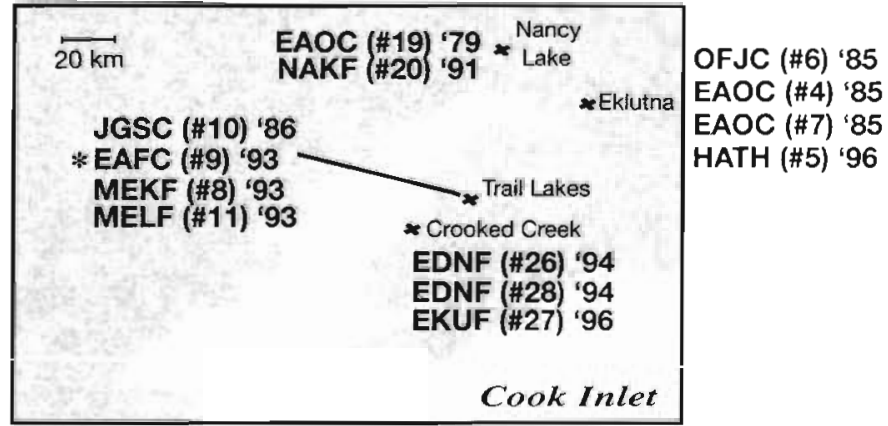

Fig. 6. Composite haplotypes of isolates from selected sites are displayed on an Alaska map and an inset map of Cook Inlet. Alaska. Location names are followed by the composite haplotype, the isolate number (\#) in parentheses and the year of isolation for each isolate located at that site. The * indicates the 2 isolates with identical composite haplotypes that were not located at the same site due to an RPA artifact 
composite haplotype of AAKI (Isolate 17), indicating that a different strain of IHNV had infected this portion of the returning spawning adults. Further, in 1982 a virus (\# 15) isolated from sockeye in the Gulkana River had a completely different composite haplotype of $B H Q C$. This is clear evidence of 3 different virus strains at a single location over a 13 yr period.

At the Kitoi Bay Hatchery on Kodiak Island, 2 of the 3 isolates analyzed by RPA had the identical composite haplotype of CAPE. These included IHNV from a 1982 juvenile chum fry outbreak (\# 14) in the Spring and later that Fall the wild kokanee in the hatchery water supply that were tested (\#12). A third Kitoi Bay Hatchery virus (\# 13) isolated in 1991 from another juvenile chum outbreak had a distinctly different composite haplotype (TBBE).

In the Eklutna watershed, 2 of the 4 isolates analyzed had identical composite haplotypes. In the fall of 1985 at Eklutna Lake, which supplied the water for the hatchery, wild kokanee had IHNV (\# 4) with a composite haplotype of EAOC. Later that year chum adults returning to the hatchery tested positive for IHNV (\# 7) with the identical composite haplotype. Previously that year in the spring, the chum fry from the same stock had an IHN outbreak at the hatchery (\#6) with a composite of OFJC. This suggests that the wild kokanee upstream were the likely source of the 1985 virus present in the Fall hatchery returns, but not for the spring 1985 epizootic. Interestingly, 6 yr earlier a 1979 isolation of a virus (\# 19) in a wild sockeye returning to Nancy Lake, located $40 \mathrm{~km}$ away, had the identical composite haplotype of EAOC as the two 1985 isolates from Eklutna Hatchery. The fourth isolate from Eklutna Hatchery was from sockeye fry in 1996 with a composite of HATH (\#5). Thus, again we identified 3 different virus strains (different in 3 out of the 4 probes) at a single location, but in this case we also found 3 isolates with identical composite haplotypes from different host species in the area over a 6 yr period.

\section{Sequencing of Alaskan isolates}

The sequencing of the full-length NV gene (364 bases) and a $301 \mathrm{bp}$ region of the $\mathrm{G}$ gene, henceforth referred to as the midG region, resolved the 42 isolates into 16 and 15 nucleotide sequence groups, respectively (Table 1). A pairwise comparison of the Alaska isolates sequence data determined that the maximum nucleotide diversity of the isolates was $2.75 \%$ (10 mismatches) for the NV gene, and $1.99 \%$ (6 mismatches) for the midG gene region. The maximum pairwise amino acid (aa) diversity was 4 aa for the NV protein and 2 aa for the region analyzed within the glycoprotein.
By combining the midG and full-length NV sequences for each of the 42 virus isolates, 26 different nucleotide sequences were distinguished. Phylogenetic analyses of the combined midG/NV nucleotide sequences discerned only 2 significant evolutionary relationships using parsimony and distance matrix programs (trees not shown). The isolates (nos. 39 and 42) from the Beaver Falls Hatchery were placed consistently on a terminal branch with a bootstrap confidence value of $99 \%$. The 3 isolates (nos. 12, 13, and 14) from Kitoi Hatchery were grouped together with a bootstrap value of $90 \%$. All other bootstrap values for the consensus tree were non-significant, ranging from 1 to $55 \%$. Therefore, no other evolutionary relationships could be determined from the 665 nucleotides analyzed for each virus isolate from Alaska.

To assess the genetic relationships between the Alaskan IHNV isolates and those from elsewhere in the geographic range of the virus, a more extensive phylogenetic analysis was performed including comparable midG/NV sequences of 10 previously characterized IHNV strains from Washington, Oregon, Idaho, and California (Nichol et al. 1995). The analysis also included 2 British Columbia IHNV sequences that were the most common in British Columbia and a representative isolate from seapen reared Atlantic salmon Salmo salar near Vancouver Island (E. D. Anderson, G. Trayler \& G.K. unpubl.). A phylogenetic tree including 4 Alaskan isolates selected to represent the phylogenetic positions of all the Alaskan sequences is shown in Fig. 7. The WRAC strain from Idaho was designated as the outgroup in this unrooted tree because it had the highest number of nucleotide differences from the Alaskan sequences. A tree of identical topography was also obtained using the California SRCV isolate as the outgroup (data not shown). The 10 IHNV strains selected from the study by Nichol et al. (1995) showed the same relationships at the terminal nodes of the tree as reported previously. All of the Alaskan IHNV sequences grouped with isolates from British Columbia, Washington, and Oregon with a bootstrap confidence value of $66 \%$. This grouping was distinct from the Idaho and California isolates that branched off with a bootstrap value of $87 \%$. Within the large grouping that included the Alaskan isolates there were 3 clusters supported by significant bootstrap values. The majority of the Alaskan isolates including the 3 isolates from Canadian stocks were represented by the 2 sequences Common 4 and Common 6 , and formed a cluster with the seapen isolate from British Columbia (Fig. 7, Cluster 2). Two Alaskan isolates from the Beaver Falls Hatchery that fell outside this subgroup were most closely related to the sequence representing the majority of British Columbia IHNV isolates (Fig. 7 , Cluster 3). The other Alaskan sequence, representing 


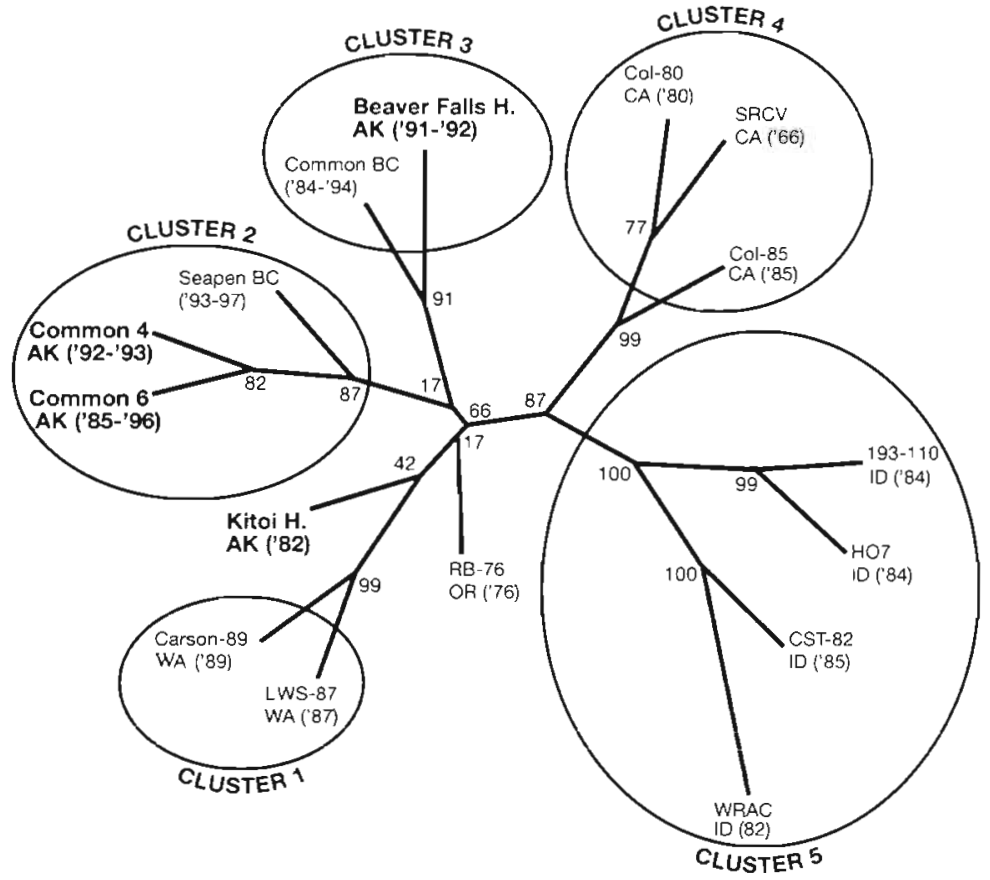

Fig. 7. Phylogenetic tree derived by maximum parsimony analysis of 665 nucleotides representing the midG/NV genes of 16 IHNV isolates. Common 4 and Common 6 sequences were selected as the most representative of 19 out of 26 mid-G/NV sequences found among the Alaskan isolates. The consensus tree was unrooted with the WRAC isolate designated as the outgroup. Bootstrap confidence values were calculated using 1000 resampled data sets and are listed at the branch nodes as percentages. Values above $70 \%$ are considered significant. A tree with identical topography was generated by neighbor-joining analysis for confimation (not shown). Isolates are listed by name, abbreviated name of state or province isolation occurred in, and in parentheses the year or years of isolation. The Alaskan isolates are listed in bold

Kitoi Bay Hatchery isolates from Kodiak Island, was placed near the mid-Columbia River isolates from Washington and Oregon, but had a low bootstrap value $(42 \%)$.

\section{DISCUSSION}

Using the RPA methodology, we analyzed 3 fulllength genes of 42 IHNV isolates from Alaska. Based on the RPA results, the trends in haplotype frequency and variability of the different gene regions could be assessed. The 3' region of the $\mathrm{N}$ gene (bases 379 to 1289) was more conserved than the $5^{\prime}$ end of the $\mathrm{N}$ gene (bases 1 to 768 ). This trend was demonstrated by the N3 gene probe delineating 15 haplotypes compared to the 22 N5 haplotypes. Further, the majority of the isolates $(57 \%)$ belonged to the single N3 haplotype A and there were fewer unique N3 haplotypes (29\%) determined than for the N5 probe $(40 \%)$, which sug- gested that the $5^{\prime}$ end of the gene was more variable. Kissi et al. (1995) sequenced the full length $N$ gene of 69 rabies virus isolates and determined that the most variable region, approximately 400 bases, was also located in the amino terminus of the $N$ gene. Among the Alaskan isolates, the $G$ gene revealed no large-sized haplotype groups, but this may be due to the full-length GF probe being longer $(-1600 \mathrm{bp})$ than the other probes. A longer probe will contain more detectable mismatches and therefore may delineate more haplotypes. The NV gene had 2 large haplotypes, representing $53 \%$ of the isolates, out of the total 10 haplotype groups determined, and there were very few unique haplotypes (5\%). This indicated that though the NV gene has some genetic diversity, certain haplotypes dominated over time. In future studies analyzing the genetic heterogeneity of IHNV genes it will be interesting to see if the conservation of the NV gene and the 3' end of the $\mathrm{N}$ gene continues to persist.

Linkages between virus genetic variability and associated parameters have been previously demonstrated with RNA viruses and can aid in deciphering viral transmission patterns (Kew \& Nathanson 1995). For the Alaskan isolates, there was no apparent correlation between haplotype and host species, life history, or stock origin (wild or hatchery). However, all 3 genes of Alaskan IHNV isolates analyzed by RPA demonstrated a consistent geographic distribution. Virus isolates belonging to the large and intermediate-sized haplotypes groups were distributed throughout Alaska, whereas isolates in small haplotype groupings were generally obtained from 1 site (hatchery, lake, etc.) or from a nearby location. In our study, no spatial relationships were found between regions or bodies of water (i.e. Southeast Alaska or Cook Inlet) and the large haplotype groups.

The maximum genetic diversity among the Alaskan isolates from both the midG region and NV gene sequences was low (1.99 and $2.75 \%$ respectively). This is in contrast to the maximum diversity (5.6 and $4.4 \%$ ) determined from nucleotide sequences of the midG and NV genes of 12 diverse IHNV isolates sampled from Washington, Oregon, Idaho, and California within the Columbia and Sacramento River basins (Nichol et al. 1995). Similarly, Oshima et al. (1995) determined by T1 ribonuclease fingerprint patterns that 26 IHNV genomes sampled from fish in the western USA had less than $5 \%$ genetic variability. Thus, the Alaskan IHNV isolates appeared to be less diverse at the genetic level than the isolates characterized by Nichol et al. (1995) or Oshima et al. (1995) despite the much larger number of Alaskan isolates from different stocks 
and a greater number of watersheds that were analyzed. Phylogenetic analysis of the full length $G$ and NV genes of the 12 isolates analyzed by Nichol et al. (1995) indicated that genetic relatedness correlated with geographic location and not with host species or time of isolation. In that study, the distance between the mouths of the Columbia and Sacramento Rivers is approximately $1010 \mathrm{~km}$ with a $9^{\circ}$ latitude difference, while our study included isolates from a coastal range of approximately $2150 \mathrm{~km}$, but with the majority of the isolates within a $5^{\circ}$ latitude range. In our analysis, phylogenetic insights into the evolutionary history of the 42 Alaskan sequences were limited, since only 2 terminal clades were significant in the consensus tree. However, our broader analysis of 4 representative Alaskan sequences with the majority of the isolates analyzed by Nichol et al. (1995) and representative sequences present in British Columbia, Canada (Anderson et al. unpubl.) generated a consensus tree with several significant bootstrap values indicating valid evolutionary relationships (Fig. 7). It was interesting to note that the Alaskan isolates from Beaver Falls hatchery, located at the southern-most end of the Alaska panhandle, grouped with the most common $\mathrm{BC}$ sequence and that the most prevalent Alaskan sequences clustered with the $\mathrm{BC}$ seapen isolates. These results indicate an overall genetic continuity between Alaskan and BC IHNV isolates and that both these subgroups may have been derived from a common ancestral viral lineage.

Our study documents that the genetic diversity of IHNV within Alaska is notably lower than IHNV in the more southern portions of its North American range. There are many possible hypotheses for this observation. The low diversity may be related to fish culture practices in Alaska. Alaska's aquaculture program is relatively young and it adheres to stringent culture techniques to control IHNV. The state government has strict guidelines on the transfer of fish stocks within the state, very few stocks have been imported into the state, and there has been a regulatory ban on fish importation for over 20 yr. Further, healthy wild salmon stocks still exist in Alaska. This decreases the need for hatcheries that can create a conducive environment (crowding, lower water quality, etc.) for virus outbreaks to occur. Less intense aquacultural activity in Alaska may contribute to the low genetic heterogeneity demonstrated by Alaskan IHNV isolates. In contrast, when isolates from the Columbia and Sacramento River basins, watersheds with a higher number of salmonid enhancement programs and mixed stock fish transfers, were examined, the level of genetic diversity increased and genetic relatedness correlated with geographic origin (Nichol et al. 1995).

In addition, the physical oceanographic features of the Gulf of Alaska (i.e. a small gyre associated with higher zooplankton productivity) and the Bering Sea (i.e. a large continental shelf) could provide environments for intermingling of different Alaskan salmonid stocks that may lead to a genetic homogenization of IHNV within Alaska. The greater depth and larger gyre in the Pacific ocean between the Columbia and Sacramento rivers may be conducive to a more open ocean migration of these stocks, possibly resulting in less interaction between salmonid stocks and their associated virus strains. In association with the oceanographic features, the migration patterns of a salmonid species/stock during their marine residency would likewise be a factor if any ocean encounter were to occur. The possible marine reservoir or much debated carrier-state of IHNV could also play a role in the transmission of different virus strains to salmonids in saltwater (Traxler et al. 1997, Kent et al. 1998, Meyers 1998).

Another consideration is that the majority of IHNV detected in Alaska is from sockeye salmon, whereas in the more Southern portion of the viral range IHNV is isolated primarily from steelhead, rainbow trout, and chinook. Therefore the low genetic diversity observed in Alaskan IHNV may be due, at least in part, to host specific factors involved with replication and adaptation to sockeye. Further, it should be noted that the Alaskan IHNV isolates were primarily from coastal salmonid stocks, which could lead to higher straying and thus prevent reproductive isolation of the virus within a stock (Pascual \& Quinn 1993). In contrast, the Sacramento River salmonid stock travel approximately 500 river $\mathrm{km}$ back to their natal streams and the non-anadromous farmed rainbow trout from the Snake River are approximately 1500 river $\mathrm{km}$ upstream from the mouth of the Columbia River. These factors could cause reproductive isolation of the host stocks and may contribute to the higher genetic diversity seen between the IHNV isolates studied from these regions (Nichol et al. 1995, R. Troyer \& G.K. unpubl.). This suggests that when trying to determine if correlations exist between the geographic origin and sequence diversity of IHNV isolates, the spatial scale that is being examined can affect the level of phylogenetic resolution. Phylogenetic analysis of the hypervariable region of the phosphoprotein for New Jersey vesicular stomatitis virus (VSV-NJ) isolates sampled from distant areas (North and South America) grouped the isolates into different geographic lineages (Rodriguez et al. 1996). However, when VSV-NJ isolates from within a smaller area (Costa Rica) were analyzed, distinct genetic lineages were correlated with ecological zones (moist highlands or dry lowlands) and not the isolates' geographic proximity to one another (Rodriguez et al. 1996). It may be relevant in future studies 
that examine IHNV genetic diversity to compare the resultant heterogeneity with the ecological zones (e.g. spawning grounds) inhabited by their salmonid host when analyzing isolates from a smaller spatial scale (e.g. watershed).

Interestingly, RPA analysis of the Alaskan isolates, in addition to demonstrating some spatial correlations with haplotypes, also elucidated a possible temporal pattern with the $\mathrm{G}$ gene haplotypes (Fig. 5). The $\mathrm{G}$ gene haplotypes were present for a contiguous interval and then were absent. This stair-step pattern of appearance and disappearance of $\mathrm{G}$ gene haplotypes may indicate that the glycoprotein, in response to selective pressure by the host immune system, needs to change through time. The rabies, influenza, and viral hemorrhagic septicemia virus glycoproteins have also been suggested to be driven by strong positive selection (Webster et al. 1992, Benmansour et al. 1997. Kissi et al. 1999). The absence of any dominant G gene haplotype in our analysis (Table 2) supports the hypothesis that the $G$ gene maintains a higher level of genetic diversity than other IHNV genes and this was also reflected in the evolving haplotype pattern. This temporal pattern has also been demonstrated in other virus genetic diversity studies. The unique regions of a VP1 capsid protein of 23 parvovirus B19 strains were analyzed by a non-isotopic RNase cleavage assay and by nucleotide sequencing (Haseyama et al. 1998). The strains were categorized into 3 types. The presence and absence of each type was sequential and the authors suggested a change had occurred from one type to another. Human respiratory syncytial virus $G$ gene sequences from isolates sampled worldwide since 1956, also clustered temporally, but not spatially (Cane \& Pringle 1995). A successful IHNV glycoprotein, based on a specific genetic type, may be present for a set period, but as the host defense systems adapt the viral glycoprotein must also acclimate in order for the virus to continue to be an effective pathogen.

In addition to spatial and temporal correlations, epidemiological insights could be suggested from the results. Genetic characterization of multiple isolates from individual sites can aid in inferring whether IHNV is evolving over time and/or if exogenous sources are responsible for the prosence of different strains at these sites. For our study we inferred that viral introduction from independent sources most likely occurred if 2 isolates from the same site differed in 3 or 4 of the individual haplotype groupings. Alternatively, we speculated that viral evolution was most likely occurring if 2 isolates from the same site differed by only 1 of the individual gene haplotypes (e.g. MEKF and MELF). There were 10 sites where multiple virus isolates were analyzed (Table 1). Seven of the sites (Chenik Lake, Eklutna Lake, Trail Lakes Hatchery,
Kitoi Bay Hatchery, Gulkana River, Crooked Creek Hatchery, and Beaver Falls Hatchery) had at least 2 isolates that differed in only 1 haplotype, indicating evolution events. Eight of the sites (Chenik Lake, Eklutna Lake, Trail Lakes Hatchery, Kitoi Bay Hatchery, Gulkana River, Nancy Lake, Auke Lake, and Klawock Hatchery) had isolates that differed in 3 or 4 of the individual haplotypes, indicating introduction from independent sources. This suggested that both viral evolution and viral introductions contribute significantly to the heterogeneity of IHNV at various hatcheries and watersheds in Alaska. Several sites appear to have both viral diversification mechanisms (introduction and evolution) occurring. For example, the 4 virus isolates from the Trail Lakes Hatchery (nos. 8 to 11) have composite haplotypes JGSC (1986), EAFC (1993), MEKF (1994), and MELF (1994). These indicate 3 independent virus sources and 1 evolutionary event within the 8 yr betwcen 1986 and 1994 (Table 1).

Evidence that genetic stasis of IHNV can also occur was provided by the identification of isolates with identical composite haplotypes and midG/NV sequences at sites where multiple isolates were analyzed. Out of 5 identical composite haplotype sets, 4 were located at the same site or in close proximity (Fig. 6). At Crooked Creek and Gulkana Hatcheries pairs of isolates sampled from different locations or years that had identical composite haplotypes and sequences indicated that virus incidence (i.e. genetic types) may be 'watershed-based' in some cases. At both Kitoi Bay and Eklutna hatcheries identical virus pairs were found in hatchery fish and from wild fish in the hatchery water supply, providing evidence for a transmission link between these 2 host populations. Further evidence of genetic stasis was the identification of a virus identical to the Eklutna strains from nearby Nancy Lake, but isolated 6 yr earlier. These examples of stasis and the overall low sequence heterogeneity of the Alaskan isolates suggest that they are evolutionarily constrained.

Since only the midG/NV genes were sequenced and the phylogenetic analysis of the Alaskan isolates alone was not informative, it may be valuable to determine if other regions of the genome are also highly variable. These regions could be sequenced and used in conjunction with the whole gene RPA analysis. In the future, the rapidly developing gene chip technology could be utilized to perform whole genome analysis of selected IHNV strains to identify highly variable regions of the genome that may be more informative. Holmes (1998) suggested that in order to properly determine the molecular epidemiology of viruses, complete viral genomes needed to be sequenced in order to delineate appropriate virological markers for true determination of strain-disease associations. 
This study establishes a baseline of genetic fingerprint patterns and sequence groups representing the genetic diversity of Alaskan IHNV isolates. In the future, this information could be used to facilitate decisions in fisheries management, such as stock transfers both between and within watersheds and rearing of certain stocks at hatcheries, in order to avoid transferring different virus strains. This practice would prevent the introduction of a new virus strain into an environment with susceptible resident fish stocks. Isolates from future IHN outbreaks can be compared against this genetic database and the potential source of the virus could be identified.

Acknowledgements. Bill Batt's technical expertise in nucleotide sequencing and cell culture considerably hastened our laboratory work. A special thanks to Dr Jim Winton for his insightful scientific and editorial comments on this manuscript. We hope that the final semantics are pleasing.

\section{LITERATURE CITED}

Banerjee AK, Barik S (1992) Gene expression of vesicular stomatitis virus genome RNA. Virology 188:417-428

Benmansour A, Basurco B, Monnier AF, Vende P, Winton JR, dekinkelin P (1997) Sequence variation of the glycoprotein gene identifies three distinct lineages within field isolates of viral haemorrhagic septicaemia virus, a fish rhabdovirus. J Virol 78:2837-2846

Cane PA, Pringle CR (1995) Molecular epidemiology of human respiratory syncytial virus. Semin Virol 6:371-378

Engelking HM, Leong JC (1989) The glycoprotein of infectious hematopoietic necrosis virus elicits neutralizing antibody and protective responses. Virus Res 13:213-230

Felsenstein J (1993) PHYLIP (Phylogeny Inference Package) version 3.5c. Distributed by the author Department of Genetics, University of Washington, Seattle

Fijan N, Sulimanovic' D, Bearzotti M, Muzinic' D, Zwillenberg LO, Chilmonczyk S, Vautherot JF, deKinkelin $\mathrm{P}$ (1983) Some properties of the epithelioma papulosum cyprini (EPC) cell line from carp, Cyprinus carpio. Ann Virol (Paris) 134E:207-220

Follett JE, Thomas JB, Hauck AK (1987) Infectious hematopoietic necrosis virus in moribund and dead juvenile chum, Oncorhynchus keta (Walbaum) and chinook, $O$. tshawytscha (Walbaum), salmon and spawning adult salmon at an Alaskan hatchery. J Fish Dis 10:309-313

Gilman M (1994) Preparation and analysis of RNA. In: Ausbel FM (ed) Current protocols in molecular biology. John Wiley \& Sons, New York, p 4,2.4-4.2.8

Haseyama K, Kudoh T, Yoto Y, Suzuki N, Chiba S (1998) Analysis of genetic diversity in the VP1 unique region gene of human parvovirus B19 using the mismatch detection method and direct nucleotide sequencing. J Med Virol 56:205-209

Hillis DM, Bull JJ (1993) An empirical test of bootstrapping as a method for assessing confidence in phylogenetic analysis. Syst Biol 42:182-192

Holmes EC (1998) Molecular epidemiology of dengue virusthe time for big science. Trop Med Int Health 3:855-856

Hsu Y, Engelking M, Leong JC (1986) Occurrence of different types of infectious proteins of infectious hematopoietic necrosis virus. Fish Pathol 20:331-336
Huang C, Chien MS, Landolt M, Batts W, Winton J (1996) Mapping the neutralizing epitope on the glycoprotein of infectious hematopoietic necrosis virus, a fish rhabdovirus. J Gen Virol 77:3033-3040

Kent ML, Traxler GS, Kieser D, Richard J, Dawe SC, Shaw RW, Prosperi-Porta G, Ketcheson J, Evelyn TPT (1998) Survey of salmonid pathogens in ocean-caught fishes in British Columbia, Canada. J Aquat Anim Health 10: 211-219

Kew O, Nathanson $N$ (1995) Introduction: Molecular epidemiology of viruses. Semin Virol 6:357-358

Kissi B, Tordo N, Bourhy H (1995) Genetic polymorphism in rabies virus nucleoprotein gene. Virology 209:526-537

Kissi B, Badrane H, Audry L, Lavenu A, Tordo N, Brahimi M, Bourhy $H$ (1999) Dynamics of rabies virus quasispecies during serial passages in heterologous hosts. J Gen Virol 80:2041-2050

Kurath G, Leong JC (1985) Characterization of infectious hematopoietic necrosis virus mRNA species reveals a nonvirion rhabdovirus protein. J Virol 53:462-468

Kurath G, Ahern KG, Pearson GD, Leong JC (1985) Molecular cloning of the six mRNA species of infectious hematopoietic necrosis virus, a fish rhabdovirus, and gene order determination by R-loop mapping. J Virol 53:469-476

Kurath G, Higman KH, Bjorklund HV (1995) The NV genes of fish rhabdoviruses: development of RNase protection assays for rapid assessment of genetic variation. Vet Res $26: 477-485$

Meyers TR (1998) Healthy juvenile sockeye salmon reared in virus-free hatchery water return as adults infected with infectious hematopoietic necrosis virus (IHNV): a case report and review of controversial issues in the epizootiology of IHNV. J Aquat Anim Health 10:172-181

Meyers RM, Larin X, Maniatis T (1985) Detection of single base substitutions by ribonuclease cleavage at mismatches in RNA/DNA duplexes. Science 230:1242-1246

Meyers TR, Thomas JB, Follett JE, Saft RR (1990) Infectious hematopoietic necrosis virus: trends in prevalence and the risk management approach in Alaskan sockeye salmon culture. J Aquat Anim Health 2:85-98

Nichol ST, Rowe JE, Winton JR (1995) Molecular epizootiology and evolution of the glycoprotein and non-virion protein genes of infectious hematopoietic necrosis virus, a fish rhabdovirus. Virus Res 38:159-173

Oberg LA, Wirkkula J, Mourich D, Leong JC (1991) Bacterial expressed nucleoprotein of infectious hematopoietic necrosis virus augments protective immunity induced by the glycoprotein vaccine in fish. J Virol 65:4486-4489

Oshima KH, Arakawa CK, Higman KH, Landolt ML, Nichol ST, Winton JR (1995) The genetic diversity and epizootiology of infectious hematopoietic necrosis virus. Virus Res 35:123-141

Pascual MA, Quinn TP (1993) Geographical patterns of straying of fall chinook salmon, Oncorhynchus tshawytscha (Walbaum), Columbia River (USA) hatcheries. In: Heggbergt TG (ed) Homing and straying in salmon, Vol 25 (2 Suppl). Blackwell Scientific Publications, Oxford, p 17-30

Rodriguez LL, Fitch WM, Nichol ST (1996) Ecological factors rather than temporal factors dominate the evolution of vesicular stomatitis virus. Proc Natl Acad Sci 93: $13030-13035$

Rose J, Schubert M (1987) Rhabdovirus genomes and their products. In: Wagner RR (ed) Rhabdoviruses. Plenum Press, New York, p 129-166

Salminen MO, Carr JK, Robertson DL, Hegerich P, Gotte D, Koch C, Sanders-Buell E, Gao F, Sharp PM, Hahn BH, Burke DS, McCutchan FE (1997) Evolution and probable 
transmission of intersubtype recombinant human immunodeficiency virus type 1 in a Zambian couple. J Virol 71: $2647-2655$

Sambrook J, Fritsch EF, Maniatis T (1989) Molecular cloning: a laboratory manual. Cold Spring Harbor Laboratory Press, Cold Spring Harbor, NY

Traxler GS, Roome JR, Kent ML (1997) Transmission of infectious hematopoietic necrosis virus in seawater. Dis Aquat Org 28:31-38

Walker PJ, Benmansour A, Calisher $\mathrm{CH}$, Dietzgen R, Fang RX, Jackson AO, Kurath G, Leong JC, Nadin-Davies S,

Editorial responsibility: Jo-Ann Leong,

Corvallis, Oregon, USA
Tesh RB, Tordo N (in press) Family Rhabdoviridae. In: The seventh report of the international committee for taxonomy of viruses. Springer Verlag (in press)

Webster RG, Bean WJ, Gorman OT, Chambers TM, Kawaoka $Y$ (1992) Evolution and ecology of influenza A viruses. Microbiol Rev 56:152-179

Winter E, Yamamoto F, Amoguera C, Perucho M (1985) A method to detect and characterize point mutations in transcribed genes: amplification and over expression of the mutant c-Ki-ras allele in human tumor cells. Proc Natl Acad Sci 82:7575-7579

Submitted: October 21, 1999; Accepted: January 20, 2000 Proofs received from author(s): April 4, 2000 